\title{
New insights into cardiac and brain sodium channels modulation by beta blockers
}

\author{
Mohamed Chahine ${ }^{1,2 *}$ \\ 1 Centre de Recherche, Université Laval Robert-Giffard, Québec, QC, Canada \\ 2 Departement of Medicine, Université Laval, Québec, QC, Canada \\ *Correspondence: mohamed.chahine@phc.ulaval.ca
}

\section{A commentary on}

Propranolol blocks cardiac and neuronal voltage-gated sodium channels. by Wang, D. W., Mistry, A. M., Kahlig, K. M., Kearney, J. A., Xiang, J., and George, A. L. Jr. Front. Pharmacol. 1:144. doi: 10.3389/ fphar.2010.00144.

Beta-adrenergic blocking agents known as beta blockers are widely used in clinical practice to treat several cardiovascular disorders such as hypertension and high blood pressure in general. They are also used as cardioprotective agents in post myocardial infarction, for the treatment of cardiac arrhythmias and were reported to be beneficial in treating migraine. Recently, they were shown to be efficacious in treating patients with several types of congenital long QT syndromes and in patient with catecholaminergic polymorphic ventricular tachycardia.

They mainly act by antagonizing the effects of norepinephrine released from sympathetic nerve endings on beta adrenoceptors. A direct interaction with ion channels in addition to the beta blocking property is now becoming more and more accepted in the scientific community. Propranolol is the beta blocker prototype, it is commonly used as racemic mixture with equal concentrations of R-(+)- and S-(-)-enantiomers. Although, they have been classified as class II antiarrhythmic drugs by Vaughan Williams the molecular mechanisms by which they act is not fully elucidated. On the other hand, their beneficial effect in preventing migraine is not well understood.

Earlier electrophysiological studies have reported the effects of propranolol on heart rate and conduction properties in frog auricular fibers, rat, and canine ventricular myocytes. Recent data have shown that beta blockers could modulate $\mathrm{Na}_{\mathrm{v}} 1.5$, the cardiac voltage-gated sodium channels, but the effect on the expressed brain sodium channels was not envisaged. In the paper by Wang et al., the authors studied the effect of propanol on heterologously expressed recombinant human cardiac $\left(\mathrm{Na}_{\mathrm{v}} 1.5\right)$ and the three brain $\left(\mathrm{Na}_{\mathrm{v}} 1.1, \mathrm{Na}_{\mathrm{v}} 1.2\right.$, and $\left.\mathrm{Na}_{\mathrm{v}} 1.3\right)$ sodium channels using whole-cell patch clamp recordings.

Previous work from the author's group showed that racemic propranolol and $\mathrm{R}$-(+)-propranolol block $\mathrm{Na}_{\mathrm{v}} 1.5$ channels (Wang et al., 2008). In this paper the authors extended their study to evaluate the molecular mechanism of the reported block. Both $\mathrm{R}-(+)$ and S-(-) propranolol block $\mathrm{Na}_{\mathrm{v}} 1.5$ sodium channels in tonic and phasic (usedependent or frequency-dependent) manner with similar affinities. However, nadolol a non-selective beta blocker and metoprolol a selective beta 1 blocker did not induce any tonic or phasic block, suggesting that the sodium channel block property is not common to all beta blockers. More detailed biophysical studies from the authors revealed that that $\mathrm{R}-(+)$-propranolol exhibits biophysical effects on $\mathrm{Na}_{\mathrm{v}} 1.5$ that are similar but not identical to lidocaine, the class 1 antiarrhythmic drug prototype. That R-(+)-propranolol acts as a typical local anesthetic and class 1 antiarrhythmics on sodium channels by interacting with specific residues in the DIV-S6 segment, including the phenylalanine-1760, known to play a central role in drug binding (Ragsdale et al., 1994) and therefore shares this property with established antiarrhythmic drugs. Finally, further detailed biophysical study from the authors showed that the brain sodium channels $\left(\mathrm{Na}_{\mathrm{v}} 1.1\right.$, $\mathrm{Na}_{\mathrm{v}}$ 1.2, and $\mathrm{Na}_{\mathrm{v}} 1.3$ ) exhibit less sensitivity to $\mathrm{R}-(+)$-propranolol than the $\mathrm{Na}_{\mathrm{v}} 1.5$ channels. Since the phenylalanine-1760 is a conserved residue in all sodium channels, including brain sodium channels, studies to elucidate the basis of this reduced affinity at molecular level are warranted.

These data reported by Wang et al., in this issue of Frontiers in Pharmacology of Ion Channel and Channelopathies, will pave the path toward a more understanding of the effect of beta blockers on sodium channels, a widely used class of drugs.

\section{ACKNOWLEDGMENTS}

This study was supported by grants from the Heart and Stroke Foundation of Québec (HSFQ) and the Canadian Institute of Health Research (CIHR, MT-13181).

\section{REFERENCES}

Ragsdale, D. S., McPhee, J. C., Scheuer, T., and Catterall, W. A. (1994). Molecular determinants of state dependent block of $\mathrm{Na}+$ channels by local anesthetics. Science 265, 1724-1728.

Wang, D. W., Crotti, L., Shimizu, W., Pedrazzini, M. Cantu, F., De, F. P., Kishiki, K., Miyazaki, A., Ikeda, T., Schwartz, P. J., and George, A. L. Jr. (2008). Malignant perinatal variant of long-QT syndrome caused by a profoundly dysfunctional cardiac sodium channel. Circ. Arrhythm. Electrophysiol. 1, 370-378.

Received: 03 January 2011; accepted: 05 January 2011; published online: 19 January 2011.

Citation: Chahine M (2011) New insights into cardiac and brain sodium channels modulation by beta blockers. Front. Pharmacol. 2:1. doi:10.3389/fphar.2011.00001

This article was submitted to Frontiers in Pharmacology of Ion Channel and Channelopathies, a specialty of Frontiers in Pharmacology.

Copyright (c) 2011 Chahine. This is an open-access article subject to an exclusive license agreement between the authors and Frontiers Media SA, which permits unrestricted use, distribution, and reproduction in any medium, provided the original authors and source are credited. 